\title{
PREDICTION AND MINIMIZATION OF LABOR COSTS FOR TECHNICAL SERVICES OF MACHINERY AND EQUIPMENT IN LIVESTOCK
}

\author{
ПРОГНОЗИРОВАНИЕ И МИНИМИЗАЦИЯ ТРУДОВЫХ ЗАТРАТ НА ТЕХНИЧЕСКИЙ \\ СЕРВИС МАШИН И ОБОРУДОВАНИЯ В ЖИВОТНОВОДСТВЕ
}

\section{Kovalev, Candidate of Economic Sciences, Associate Professor}

Л.И. Ковалёв, кандидат экономических наук, доцент

\author{
I. Kovalev, Engineer-Economist \\ И.Л. Ковалёв, инженер-экономист
}

\begin{abstract}
Belarusian State Agrarian Technical University, Minsk, Republic of Belarus
Белорусский государственный аграрный технический университет, г. Минск, Республика Беларусь Phone: (+375 29) 391-51-11, (+375 29) 126-69-12
\end{abstract}

E-mail: olbosigor@mail.ru

Received June 10, 2012

\begin{abstract}
Justification is given to a technique of application for standards of an expense of resources on conventional unit of complexity and time expenses for services of livestock technical service with a view of economy of resources. Definition of expenses of working hours assumes preliminary studying and an assessment of methods and ways of performance of work, design of rational production technologies of cattle-breeding production, production and work organization. In the countries with the developed market economy methodological and material base for rationing of work of workers is created. A wide circulation receive methods of linear programming, the multiple-factor regressive analysis, versions of statistical methods for expenses studying. In this research material inputs are defined on standard to forming factors with application of the regressive analysis.
\end{abstract}

\section{АННОТАЦИЯ}

В статье дано обоснование эффективной методики применения нормативов расхода ресурсов на условную единииу категории сложности и затрат времени по группам машин и оборудования для служб технического сервиса животноводства в целях экономии трудовых и временных ресурсов. Определение необходимых затрат рабочего времени предполагает предварительное изучение и оценку существующих методов и способов выполнения работы, проектирование более рациональных, отвечающих требованиям современных технологий производства животноводческой продукции, организации производства и труда. В странах с развитой рыночной экономикой создана методологическая и материально-техническая база, позволяющая осуществлять нормирование труда практически всех категорий работников. Широкое распространение в зарубежной практике нормирования получают методы линейного программирования, многофакторный регрессивный анализ, разновидности статистических методов изучения затрат времени. В данном исследовании материальные затраты определень по нескольким нормативнообразующим факторам с применением регрессивного анализа и установлень зависимости для определения материальных затрат на техническое обслужсивание и ремонт по группам машин и оборудования в животноводстве.

\section{KEY WORDS}

Dairy cattle; Specifications; Scheduling; Workload; Equipment; Maintenance service; Repair service. КЛЮЧЕВЫЕ СЛОВА

Молочное скотоводство; Нормативы; Планирование; Трудоемкость; Техника; Техническое обслуживание; Ремонт. 
Методы интенсивного ведения сельского хозяйства в условиях рынка неразрывно связаны с использованием достижений научнотехнического прогресса, усилением режима экономии всех видов ресурсов и повышением научного уровня планирования любой производственной деятельности сельхозтоваропроизводителей. Решение этих задач практически невозможно без создания прогрессивной нормативной базы для планирования и постоянного ее совершенствования.

Прогрессивные нормы и нормативы являются фундаментом разработки бизнеспланов, позволяют максимально учесть резервы производства и повышение его эффективности. С помощью норм всегда можно уста- новить максимально допустимый уровень материальных, трудовых и финансовых затрат в планируемом периоде.

Многолетний опыт работы животноводческих хозяйств, районных СТОЖ и специализированных сервисных служб, а также проводимые исследования по техническому обслуживанию и ремонту техники в животноводстве показывает, что разработка трудовых, материальных и стоимостных нормативов значительно отстает от современного обеспечения сельского хозяйства техникой и тем самым затрудняет планирование затрат на выполнение ремонтно-обслуживающих работ в хозяйствах и специализированных служб (таблица 1).

Таблица 1 - Разрыв во времени между началом выпуска машин для животноводческих ферм и разработкой типовых норм времени на их техническое обслуживание

\begin{tabular}{|c|c|c|c|c|}
\hline Машины и оборудование & $\begin{array}{l}\text { Начало } \\
\text { серийного } \\
\text { выпуска }\end{array}$ & $\begin{array}{c}\text { Снятие с } \\
\text { производства }\end{array}$ & $\begin{array}{c}\text { Год разработки } \\
\text { типовых норм } \\
\text { времени }\end{array}$ & $\begin{array}{c}\text { Разрыв во времени ме- } \\
\text { жду серийным произ- } \\
\text { водством и разработкой } \\
\text { норм, лет }\end{array}$ \\
\hline $\begin{array}{c}\text { Доильный агрегат АДМ-8 } \\
\text { на } 200 \text { голов }\end{array}$ & 1973 & - & 1980 & 7 \\
\hline Доильная установка УД̆Т-б & 1971 & 1979 & 1980 & 9 \\
\hline Холодильная установка МХХ У-8 & 1969 & 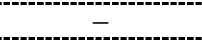 & 1975 & 6 \\
\hline $\begin{array}{c}\text { Транспортер для уборки навоза } \\
\text { ТСН-3,0Б }\end{array}$ & 1965 & - & 1975 & 10 \\
\hline $\begin{array}{c}\text { Транспортер раздатчик внутри корму- } \\
\text { шек ТВК-80A }\end{array}$ & 1962 & - & 1969 & 7 \\
\hline $\begin{array}{l}\text { Агрегат для приготовления травяной } \\
\text { муки АВM- } 0,65\end{array}$ & 1973 & 1980 & 1984 & 11 \\
\hline $\begin{array}{c}\text { Молокоохладительная } \\
\text { установка УЗМ-8 }\end{array}$ & 2010 & - & не разработаны & - \\
\hline $\begin{array}{l}\text { Резервуар-охладитель молока с непо- } \\
\text { средственным охлаждением МКЦ- } 1300\end{array}$ & 2008 & - & не разработаны & - \\
\hline $\begin{array}{c}\text { Доильная установка для доения в ведра } \\
\text { УДВ-50 }\end{array}$ & 2007 & - & не разработаны & - \\
\hline
\end{tabular}

Проводимые исследования показывают, что нормы времени на техническое обслуживание и ремонт животноводческой техники не всегда технически обоснованно устанавливаются и не соответствуют действительным затратам труда. Так, на доильный агрегат АД100 А в 1975 году разработаны и утверждены годовые затраты труда на ежедневное техническое обслуживание в количестве 780 чел.-ч, в 1980 году на доильную установку АДМ-8 на 200 голов соответственно 340 чел.-ч, в то время как трудоемкость обслуживания последней значительно выше.

В результате анализа выявлено, что нормы времени, разработанные еще в 70-90-е годы прошлого столетия разными исполнителями (организациями) на одинаковые типы машин имеют большие различия. В разработанных
«Типовых нормах времени на техническое обслуживание и ремонт машин, технологического оборудования, контрольно-измерительных приборов, средств автоматики и электрооборудования свиноводческих комплексов 54 и 108 тыс. свиней в год» (М.: ЦНИИТЭИ, 1977) на котел-парообразователь Д-721-А устаᄀновлена трудоемкость по видам обслуживания, чел.-ч: ЕTO - 0,43; ТО1 - 0,72; ТО2 - 9,75; а в «Типовых нормах времени на работы по техническому обслуживанию машин и оборудования в животноводстве, птицеводстве и на комбикормовых предприятиях» (М.: ЦНИИТЭИ, 1983) соответственно - 1,65; 8,00; 6,95.

Аналогичные явления наблюдаются в настоящее время и по другим видам машин. Это, в конечном итоге, приводит к удорожанию продукции животноводства. Поэтому, чтобы 
устранять имеющиеся недостатки, при разработке норм времени необходимо за основу принять категорию сложности технического обслуживания, ремонта машин и оборудования.

Нормативы категории сложности можно использовать при определении трудоемкости работ по техническому обслуживанию и ремонту. Научно обоснованные нормы труда создают условия для равной его интенсивности и напряженности не только на одинаковых, но и на разнородных работах.

Зная категорию сложности машин, мы можем определить годовые затраты труда на техническое обслуживание и ремонт по формуле:

$$
T=t \cdot R(1)
$$

где $T$ - трудоемкость технического обслуживания и ремонта, чел.-ч; $t$ - трудоемкость условной единицы, чел.-ч; $R$ - категория сложности технического обслуживания и ремонта машин, усл. ед.
Например, категория сложности технического обслуживания и ремонта для молокоохладительной установки УЗМ-8 определена по установленной эмпирической зависимости и равна 9,9. Подставим данные в формулу (1): T = 27 ч $\times 9,9=267,3$ чел.-ч. Следовательно, годовые затраты труда на техническое обслуживание и ремонт холодильной установки УЗМ-8 составляют 267,3 чел.-ч.

Проведем анализ сопоставления трудоемкостей определенных по «Категории сложности» с типовыми нормами времени на техническое обслуживание и ремонт машин и оборудования в животноводстве (таблица 2).

Анализируя данные табл. 2, можно сделать вывод, что трудоемкость, определенная через категорию сложности, имеет незначительное отклонение от нормативной (2-6\%) и может быть использована для определения объемов и планирования работ по техническому обслуживанию и ремонту животноводческой техники.

Таблица 2 - Отклонения трудоемкости, определенной по категории сложности от типовых норм времени на техническое обслуживание и ремонт машин и оборудования в животноводстве

\begin{tabular}{|c|c|c|c|c|c|}
\hline $\begin{array}{c}\text { Наименование машин и } \\
\text { оборудования }\end{array}$ & $\begin{array}{c}\text { Категория } \\
\text { сложности, } \\
\text { усл.ед. }\end{array}$ & $\begin{array}{c}\text { Типовые нор- } \\
\text { мативы трудо- } \\
\text { емкости на ТО } \\
\text { и ТР, чел.-ч. }\end{array}$ & $\begin{array}{c}\text { Трудоемкость, } \\
\text { определенная по } \\
\text { категории } \\
\text { сложности, чел.- } \\
\text { ч }\end{array}$ & $\begin{array}{c}\text { Абсолютное } \\
\text { отклонение от } \\
\text { нормативной } \\
\text { трудоемкости, } \\
+ \text { выше, - ниже, } \\
\text { чел.-ч. }\end{array}$ & $\begin{array}{c}\text { Погрешность } \\
\text { (отклонение) от } \\
\text { нормативной } \\
\text { трудоемкости, } \\
\%\end{array}$ \\
\hline $\begin{array}{l}\text { Доильный агрегат АДМ-8 } \\
\text { (на } 200 \text { голов) }\end{array}$ & 18,9 & 481,6 & 510,3 & $+28,7$ & 5,9 \\
\hline $\begin{array}{l}\text { Резервуар-охладитель } \\
\text { молока стационарный } \\
\text { TOM-2, ОА }\end{array}$ & 7,7 & 202,5 & 207,9 & $+5,4$ & 2,7 \\
\hline $\begin{array}{l}\text { Транспортер скребковый } \\
\text { навозоуборочный ТСН-3, } \\
\text { ОБ }\end{array}$ & 13,0 & 369,7 & 351,0 & $-18,7$ & 5,1 \\
\hline $\begin{array}{l}\text { Установка скреперная } \\
\text { УС-10 }\end{array}$ & 10,6 & 272,5 & 286,2 & $+13,7$ & 5,0 \\
\hline $\begin{array}{l}\text { Оборудование для грану- } \\
\text { лирования травяной муки } \\
\text { ОГМ-1,5 }\end{array}$ & 16,0 & 452,5 & 432,0 & $+22,5$ & 4,9 \\
\hline $\begin{array}{l}\text { Комплект оборудования } \\
\text { кормоцеха КЦС- } 2000\end{array}$ & 72,3 & 2012,7 & 1952,1 & $-60,6$ & 3,0 \\
\hline $\begin{array}{l}\text { Котел-парообразователь } \\
\text { КВ-300М }\end{array}$ & 18,9 & 498,5 & 510,3 & $+11,8$ & 2,3 \\
\hline $\begin{array}{l}\text { Электроводонагреватель } \\
\text { ВЭТ-800 }\end{array}$ & 0,8 & 22,1 & 21,6 & $-0,7$ & 3,1 \\
\hline $\begin{array}{l}\text { Автопоилка одночашеч- } \\
\text { ная ПА-ІА (на } 10 \text { шт.) }\end{array}$ & 1,5 & 38,9 & 40,5 & $+1,6$ & 4,1 \\
\hline Смеситель кормов С-7 & 5,3 & 139,1 & 143,1 & $+4,0$ & 2,9 \\
\hline Теплогенератор ТГ-2,5A & 9,8 & 271,9 & 264,6 & $-7,3$ & 2,6 \\
\hline Насос шнековый НШ & 2,8 & 72,5 & 75,6 & $+3,1$ & 4,2 \\
\hline $\begin{array}{l}\text { Вихревой насос типа } \\
\text { ВКС-1/16 }\end{array}$ & 2,1 & 60,3 & 56,7 & $-3,6$ & 5,9 \\
\hline $\begin{array}{l}\text { Оборудование автомати- } \\
\text { зированное комбикормо- } \\
\text { вых цехов ОКЦ- } 15\end{array}$ & 156,6 & 4112,8 & 4228,2 & $+115,4$ & 2,8 \\
\hline
\end{tabular}


Важно не только располагать общими затратами труда, но и структурой их распределения по видам технического обслуживания и ремонта.

Анализируя фактические отчетные данные сервисных служб и опыт передовых хозяйств о проведении технического обслуживания и ремонта животноводческой техники, а также нормативные материалы (сборники норм времени на техническое обслуживание животноводческой техники), можно сделать вывод о том, что структура затрат времени на техническое обслуживание и ремонт по группам машин имеет большие различия. Это зависит от установленной периодичности и трудоемкости выполнения работ по видам обслуживания в каждой группе машин.

Анализ показал, что в одной группе машин по технологическому назначению наблюдаются большие колебания величины затрат труда по видам технического обслуживания и ремонта. Так, например, доильный агрегат АДМ-8 на 200 голов применяется для доения коров в стойлах, трудоемкость его технического обслуживания и ремонта распределяется следующим образом: ЕТО - 72,6; ТО1 14,7 ; Т2 - 3,6 и ремонт 9,1\%. Доильная установка УДЕ-8 используется в доильных залах и трудоемкость соответственно равна 78,$6 ; 13,6 ; 1,0$ и $7,1 \%$. Поэтому необходимо все животноводческие машины и оборудование распределить по группам и структуру затрат времени на условную единицу технического обслуживания и ремонта установить для каждой группы машин.

При определении удельного веса трудоемкости по видам технического обслуживания и ремонта для каждой группы машин и оборудования расчеты проводились по формуле расчета средней арифметической:

$$
X_{a}=\sum X_{l}, X_{2}, \ldots, X_{m}: n(2)
$$

где $X_{1}, X_{2} \ldots X_{m}$ - удельный вес трудоемкости по определяемому виду технического обслуживания или на ремонт, \%; $n$ - количество машин и оборудования в рассматриваемой группе, шт.

Приведем пример расчетов на конкретных данных. Удельный вес ежедневного технического обслуживания (ЕТО) в общих годовых затратах времени технического обслуживания и ремонта составляет: по доиль- нолму агрегату АДМ-8 на 200 голов - 72,6\%; по универсальной доильной станции УДС-3А - 73,8\%; по доильной установке М-610 $73,9 \%$; по доиль-ной установке М-620 $72,8 \%$; по молокопроводу- 100 - 72,9\%; по молокопроводу-200 - 72,0\%; и по доильному агрегату АДМ-8 на 100 голов - 71,9\%. Подставим данные в формулу (2) и получим соответствующий результат:

$$
X=\frac{72,6+73,8+73,9+72,8+72,9+72,0+71,9}{7}=72,8
$$

Следовательно, в структуре затрат времени на техническое обслуживание и ремонт удельный вес трудоемкости ЕТО для доильных машин, применяемых при доении коров в стойлах, составляет 72,8\%. Аналогичным путем определялся удельный вес трудоемкости TO1, TO2 и ремонт как по каждой машине, так соответственно и по каждой группе машин и оборудования в животноводстве. На основании проведенных исследований и расчетов получены результаты для установления структуры затрат времени на техническое обслуживание и ремонт по группам машин и оборудования животноводческих ферм и комплексов (таблица 3).

Установленная структура затрат времени на одну условную единицу по группам машин позволяет определить годовые затраты труда по видам технического обслуживания и ремонта. Кроме того, это дает возможность определить необходимое количество рабочих для проведения работ по видам технического обслуживания и ремонта как в хозяйстве, так и в райагросервисе, а также распределить трудовые затраты между службами агросервиса и хозяйствами.

Приведем пример определения годовой трудоемкости по установленной структуре затрат на одну условную единицу. Для доильной установки АДМ-8 на 200 голов общая годовая трудоемкость технического обслуживания и ремонта составляет 510,3 чел.-ч. и определяется по формуле (1). Следовательно, при наличии общей трудоемкости и структуры затрат времени на техническое обслуживание и ремонт для линейных доильных установок при доении в ведро можно определить затраты труда по видам технического обслуживания и на ремонт по следующим формулам: 


$$
\begin{aligned}
T_{E T O} & =\frac{y_{E T O} \cdot T_{o \sigma}}{100} ;(3) \\
T_{T O-1} & =\frac{y_{T O-1} \cdot T_{o \sigma}}{100} ;(4) \\
T_{T O-2} & =\frac{y_{T O-2} \cdot T_{o \sigma}}{100} ;(5) \\
T_{p} & =\frac{y_{p} \cdot T_{o \sigma}}{100} ;(6)
\end{aligned}
$$

где $T_{E T O} ; T_{T O-1} ; T_{T O-2}$ и $T_{p}$ - годовые затраты труда на ежедневное техническое обслуживание, техническое обслуживание № 1, техническое обслуживание № 2 и текущий ремонт, чел.-ч; $\bigvee_{E T O} ; y_{T O-1} ; Y_{T O-2}$ и $Y_{p}-$ удельный вес трудоемкости ЕТО, ТО-1, ТО-2 и ТР в общих затратах на техническое обслуживание и ремонт машин и оборудования в животноводстве, \%; $T_{\text {об }}$ - общие годовые затраты на техническое обслуживание и ремонт, чел.-ч.

Таблица 3 - Структура годовых затрат времени на техническое обслуживание и ремонт по группам машин и оборудования в животноводстве (на одну условную единицу)

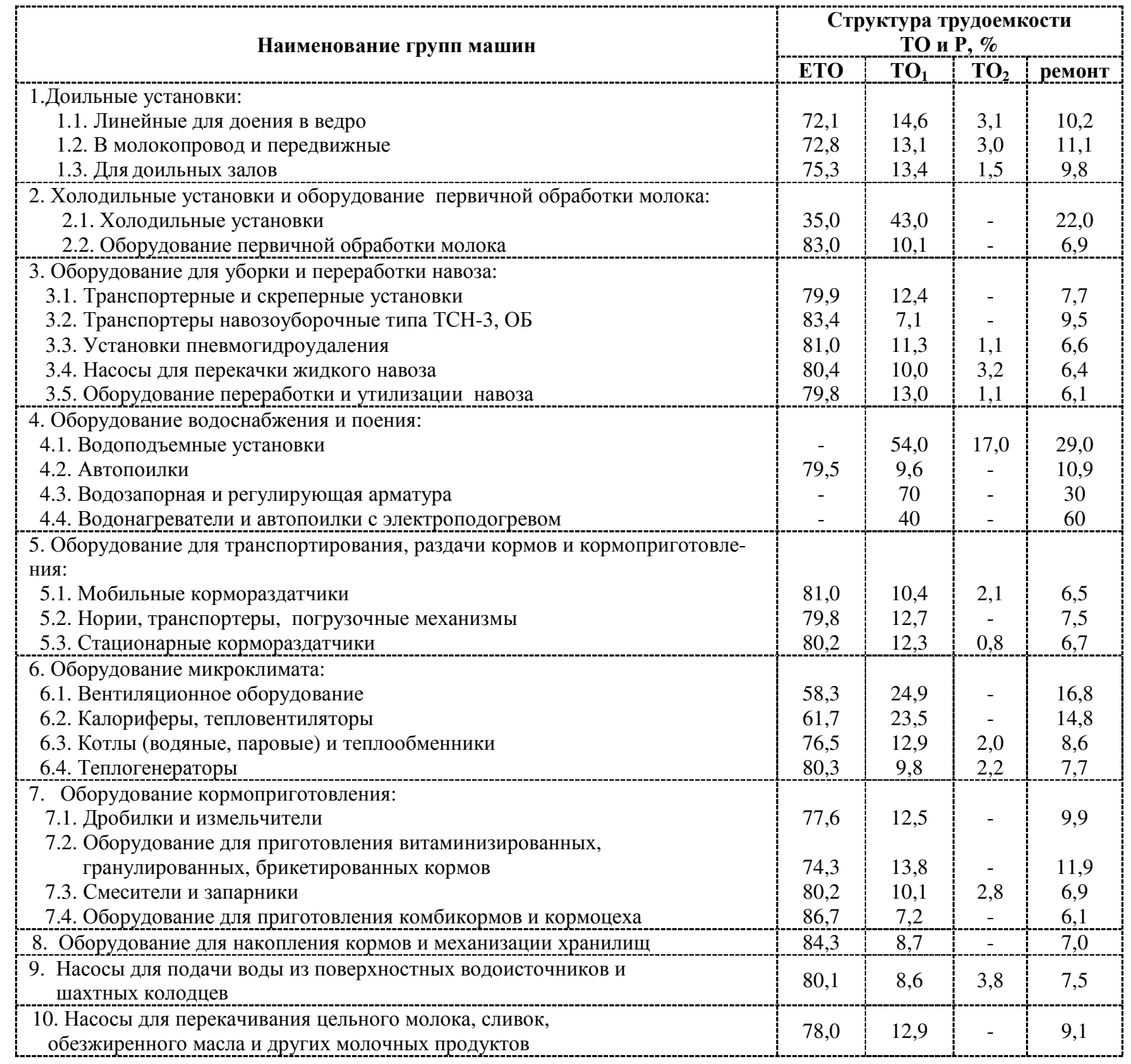

В данном примере годовые затраты труда на ежедневное техничес ᄀкое обслуживание составляют 371,5 чел.-ч. Аналогично опреде- ляется трудоемкость и по другим видам технического обслуживания и ремонта оборудования. Соответственно, зная годовую трудо- 
емкость по видам технического обслуживания и периодичность их проведения, можно определить затраты труда на проведение одного обслуживания согласно установленной периодичности по следующим формулам:

$$
\begin{gathered}
E T O=\frac{T_{E T O}}{\Pi_{E T O}} ;(7) \\
T O-1=\frac{T_{T O-1}}{\Pi_{T O-1}} ;(8) \\
T O-2=\frac{T_{T O-2}}{\Pi_{T O-2}} ;(9)
\end{gathered}
$$

где ЕТО; ТО-1; ТО-2 - затраты труда на проведение одного технического обслуживания по виду выполняемых работ, чел.-ч; ПЕТО; ПТО-1; ПТО-2 - периодичность технического обслуживания по группам машин и оборудования животноводческих ферм, количество раз в сутки (смену) месяц и в год.

Подставим данные в формулу (7) и определим затраты труда на ежедневное техническое обслуживание доильного агрегата АДМ8 на 200 голов: 1,02 чел.-ч.

На основании проведенных исследований можно сделать вывод, что предложенный метод определения трудоемкости позволяет рассчитать затраты труда по видам технического обслуживания и на ремонт на стадии создания и эксплуатации машин, оборудования животноводческих хозяйств. Это позволяет своевременно обеспечить технические сервисные службы и хозяйства нормами времени на техническое обслуживание и ремонт машин и оборудования животноводческих ферм и комплексов.

\section{БИБЛИОГРАФИЯ}

Ковалёв, Л.И. Основы организации технического сервиса машин и оборудования животноводческих ферм и комплексов/ Л.И. Ковалёв. - Минск: БГАТУ, 2011. 136 с. ил.: - ISBN 978-985-519-434-8.

Ковалёв, Л.И. Как поднять доходность сельскохозяйственного предприятия? Минск: // Экономика. Финансы. Управление. 2010, № 8,- С. 41-44.

Ковалёв, Л.И. Методические указания по применению единицы сложности для планирования затрат на техническое обслуживание и ремонт машин в животноводстве. - Минск: ВНИИТИМЖ, $1986-104$ c.

Ковалёв, Л.И. Планирование и сокращение затрат на ремонтно-обслуживающие работы в животноводческих хозяйствах/ Л.И. Ковалев, И.Л. Ковалев // Аграрное решение. - Уфа.- 2012. - №4. C.22-27.
Ковалёв, Л.И. Оптимизация издержек на техсервис машин в животноводстве / Л.И. Ковалев, И.Л. Ковалев // Эффективное животноводство. - Краснодар.2012. - № 5. - С. 62-65.

Ковалёв, Л.И. Практическое применение нормативов категорий сложности технического сервиса на стадии создания и эксплуатации машин для животноводческих хозяйств / Л.И. Ковалев, И.Л. Ковалев // Сельскохозяйственная техника: обслуживание и ремонт - М.: Сельхозиздат.- 2012. - № 6. 